\title{
Cosmetic Marketing Category
}

National Cancer Institute

\section{Source}

National Cancer Institute. Cosmetic Marketing Category. NCI Thesaurus. Code C86965.

A category specifying that a product is marketed as a cosmetic under the statutory

definition found in FD\&C Act Section 201(i) SEC. 201. [21 U.S.C. 321]. 